\title{
Erratum
}

\section{Imaging methodologies and applications for nutrition research: what can functional MRI offer? - ERRATUM}

\author{
Susan T. Francis and Sally Eldeghaidy
}

doi: 10.1017/S0029665114001530, Published by Cambridge University Press, 24 October 2014.

We regret to announce that the name and date of the conference at which this article was presented was published incorrectly. The correct conference information is below. The publishers apologise for this error.

The Nutrition Society Irish Section Meeting, University of Ulster, Coleraine. 18-20 June 2014.

Conference on 'Changing Dietary Behaviour: Physiology through to Practice'

Symposium 1: Novel imaging and other methodologies for assessing health and behaviour: applications for nutrition The error has been rectified in the online and print PDF and HTML copies of this article.

\section{Reference}

Francis ST \& Eldeghaidy S (2014) Imaging methodologies and applications for nutrition research: what can functional MRI offer? Proc Nutr Soc, published online by Cambridge University Press 24 October 2014, doi 10.1017/S0029665114001530. 